\title{
Postoperative neuro- muscular block following atracurium or alcuronium in children
}

Postoperative neuromuscular block (NMB) was evaluated in 60 children who received randomly either atracurium or alcuronium to induce and maintain an 85-95 per cent NMB during balanced anaesthesia. The EMG-monitor was turned away from the anaesthetist 10-15 min before the end of surgery. The average NMB was comparable between the groups at the time of reversal with neostigmine $50 \mu \mathrm{g} \cdot \mathrm{kg}^{-1}(84 \pm 9$ per cent, mean $\pm S D)$ as were the NMB and the train-of-four ratio when the tracheas were extubated on a clinical basis $(32 \pm 20$ per cent and $50 \pm 18$ per cent, respectively). Patients who had been paralyzed with atracurium arrived at the recovery room earlier and on arrival had greater train-of-four ratios than the patients paralyzed with alcuronium $(P<0.01)$. Time to a train-of-four ratio of $>90$ per cent was significantly shorter in the atracurium group $(10 \pm 5 \min$ vs $26 \pm 15 \mathrm{~min}, P<0.001)$. Thus, an intermediate-acting muscle relaxant offers a safer recovery profile of the NMB than a long-acting muscle relaxant in paediatric patients.

Le bloc neuromusculaire postopératoire (NMB) a été évalué chez 60 enfants avant reçu d'une façon randomisée soit l'atracurium soit l'alcuronium afin d' induire et de maintenir un NMB de 85 à 95 pour cent lors d'une anesthésie balancée. L'EMG fut tournée de l'anesthésiste 10 à 15 minutes avant la fin de la chirurgie. Le NMB moyen était comparable entre les groupes lors de l'antagonisme avec de la néostigmine $50 \mu \mathrm{g} \cdot \mathrm{kg}^{-1}$ (84 \pm

\section{Key words}

ANAESTHESIA: paediatric;

ANTAGONISTS: neuromuscular relaxants, neostigmine; COMPLICATIONS: paralysis, residual; NEUROMUSCULAR RELAXANTS: alcuronium, atracurium.

From the Department of Anaesthesiology, Children's Hospital, University of Helsinki, SF-00290 Helsinki, Finland, and the Department of Anaesthesia, Royal Children's Hospital, Parkville, Victoria 3052 Australia.

Address correspondence to: Dr. Olli Meretoja, Children's Hospital, SF-00290 Helsinki, Finland.

The financial support given by the Paulo Foundation, Helsinki, Finland, is kindly recognized.
9 pour cent, moyenne $\pm S D$ ). Il en est de même pour le NMB et le rapport de train-de-quatre quand les trachées furent extubées sur une base clinique ( $32 \pm 20$ pour cent et $50 \pm 18$ pour cent respectivement). Les patients ayant été paralysés avec l'atracurium sont arrivés plus tôt à la salle de réveil et dès leur arrivée, ils ont présenté des ratios de train-de-quatre plus élevés que ceux des patients paralysés avec l'alcuronium $(P<0.01)$. Le temps pour atteindre un ratio de train-de-quatre $>90$ pour cent était significativement plus court chez le groupe atracurium $(10 \pm 5 \min v s 26 \pm 15 \mathrm{~min}, P<0.001)$. Ainsi. un relaxant musculaire à action intermédiaire offre un profil de récupération plus sécuritaire pour le NMB que celui d'un relaxant musculaire à longue action chez les patients pédiatriques.

Early studies on postoperative residual curarization showed that as many as 40 per cent of general surgical patients expressed significant neuromuscular block in the recovery room. ${ }^{1.2}$ Recent studies in adults show that the incidence was less if either atracurium or vecuronium were used. ${ }^{3-6}$ Neuromuscular monitoring was not used consistently in any of these studies and, therefore, the differences could not be properly explained. We designed the present study to maintain a 90 per cent neuromuscular block during the course of anaesthesia when either an intermediate-acting (atracurium) or a long-acting (alcuronium) drug was used as a neuromuscular blocking agent. Alcuronium is a nondepolarizing muscle relaxant with a potency ratio to pancuronium of $1 / 3$ and clinical duration of effect comparable to pancuronium. ${ }^{7}$ Before the end of surgery, the EMG monitor was turned around and the anaesthetist reversed the residual neuromuscular block and removed the tracheal tube on a clinical basis. Neuromuscular transmission was recorded postoperatively until complete recovery of the neuromuscular block and the two relaxant groups were compared.

\section{Methods}

Sixty general surgical (ASA physical status I-II) paediatric patients who required a neuromuscular blocking agent during anaesthesia entered the study following the 
approval of the Institutional Ethical Committee. Parents gave their informed consent.

Patients received either chloral hydrate $40 \mathrm{mg} \cdot \mathrm{kg}^{-1}$ or diazepam $0.3 \mathrm{mg} \cdot \mathrm{kg}^{-1}$ as oral premedication. Sodium thiopentone $4-5 \mathrm{mg} \cdot \mathrm{kg}^{-1}$ and nitrous oxide in oxygen $2: 1$ were used to induce general anaesthesia. Surface electrodes were attached over the ulnar nerve, the adductor pollicis muscle and the base of the middle finger. The forearm was supported in a dorsal splint and the neuromuscular transmission monitor (Relaxograph, Datex, Helsinki, Finland) calibrated. Supramaximal train-offour stimuli $(2 \mathrm{~Hz})$ were used at 20 -sec intervals and the evoked adductor pollicis electromyogram recorded. Neuromuscular block (NMB) was defined as the percentage depression of the first EMG-response in the train-of-four series. Recovery data were referenced to the amplitude of the first EMG-response at the end of the study when the train-of-four ratio became $>90$ per cent.

Following a stable calibration signal, patients were allocated to receive either atracurium $0.4 \mathrm{mg} \cdot \mathrm{kg}^{-1}$ or alcuronium $0.3 \mathrm{mg} \cdot \mathrm{kg}^{-1}$ to facilitate tracheal intubation. Increments of either atracurium or alcuronium (1/4 or $1 / 5$ of the initial dose, respectively) were given to maintain NMB at 85-95 per cent during the course of anaesthesia. Fentanyl $1-2 \mu \mathrm{g} \cdot \mathrm{kg}^{-1}$ or morphine $0.1 \mathrm{mg} \cdot \mathrm{kg}^{-1}$ was

TABLE I Patient characteristics

\begin{tabular}{lcc}
\hline & $\begin{array}{l}\text { Atracurium } \\
\text { group }\end{array}$ & $\begin{array}{l}\text { Alcuronium } \\
\text { group }\end{array}$ \\
\hline Number of patients & 30 & 30 \\
Agc, yr & $6.8 \pm 4.3$ & $7.9 \pm 5.1$ \\
Body weight, kg & $26.1 \pm 17.1$ & $30.3 \pm 18.3$ \\
Duration of anaesthesia, min & $64 \pm 45$ & $74 \pm 46$ \\
\hline
\end{tabular}

Values are mean $\pm S D$. used for nociceptive reactions. No volatile inhalational agents were used. Palmar skin temperature was maintained at $>35^{\circ} \mathrm{C}$.

Ten to fifteen minutes before the end of surgery, the Relaxograph was turned around to prevent the anaesthetist from seeing the EMG-recording. From that time, the anaesthetist was unaware of the recording and treated the patient on a clinical basis. Every patient received neostigmine $50 \mu \mathrm{g} \cdot \mathrm{kg}^{-1}$ together with atropine $25 \mu \mathrm{g} \cdot \mathrm{kg}^{-1}$ to reverse the NMB at the end of surgery. Tracheal tubes were removed when spontaneous breathing and muscle power were judged to be adequate. Patients were transferred to the recovery room when the anaesthetist regarded it appropriate. Recording of the adductor pollicis EMG was continued until the train-of-four ratio had recovered to $>90$ per cent.

Statistical analysis was performed using Student's t test, Chi-square analysis, and polynomial function regression analysis, when appropriate. A $P$ value of $<0.05$ was considered statistically significant. Mean values $\pm S D$ are presented.

\section{Results}

The study groups matched for age, body weight, and the duration of anaesthesia as shown in Table 1 . All patients were 1-15 yr old and weighed $10-54 \mathrm{~kg}$. None of the patients gave any notice or felt uncomfortable that the neuromuscular monitoring was continued until the individual train-of-four ratio was $>90$ per cent. Therefore, the recordings were complete on every patient.

Table II shows the levels of NMB and train-of-four ratio at reversal, extubation and arrival at the recovery room. Although NMB was comparable at the time of reversal, the tracheas of patients who received atracurium were extubated earlier than in the patients who received

TABLE II Recovery of neuromuscular block (NMB) and train-of-four (TOF) ratio following the reversal of atracurium- and alcuronium-induced NMB. Times are calculated from the administration of neostigmine (time at reversal $=0 \mathrm{~min}$ )

\begin{tabular}{lccc}
\hline & Atracurium-group & Alcuronium-group & $P$ \\
\hline NMB at reversal (\%) & $81.6 \pm 10.6$ & $86.2 \pm 6.6$ & NS \\
Time to extubation (min) & $3.3 \pm 1.5$ & $4.3 \pm 2.1$ & $<0.05$ \\
NMB at extubation (\%) & $33.5 \pm 20.3$ & $30.9 \pm 19.7$ & NS \\
TOF at extubation (\%) & $51.8 \pm 18.5$ & $47.5 \pm 18.2$ & NS \\
Time to recovery room (min) & $7.6 \pm 1.7$ & $9.2 \pm 3.0$ & $<0.05$ \\
NMB at recovery room (\%) & $6.8 \pm 9.7$ & $10.9 \pm 15.9$ & NS \\
TOF at recovery room (\%) & $81.0 \pm 14.3$ & $68.0 \pm 19.0$ & $<0.01$ \\
& & & \\
Time to TOF $70 \%(\min )$ & $5.7 \pm 3.2$ & $12.8 \pm 14.1$ & $<0.01$ \\
Time to TOF 90\% $(\mathrm{min})$ & $10.0 \pm 4.6$ & $26.2 \pm 14.9$ & $<0.01$ \\
\hline
\end{tabular}

Values are mean \pm SD. 


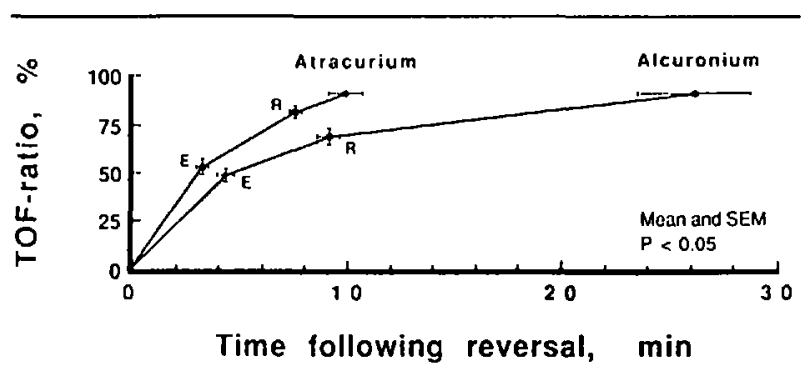

FIGURE I Recovery profiles of the train-of-four (TOF) ratio following the reversal of atracurium- and alcuronium-induced neuromuscular blocks. Neostigmine $50 \mu \mathrm{g} \cdot \mathrm{kg}^{-1}$ was given at time 0 when the average neuromuscular block was 84 per cent. The points representing extubation $(E)$, arrival in the recovery room $(R)$, and the time when a TOF ratio became 90 per cent are plotted. The TOF ratio recovered significantly faster in the atracurium group than in the alcuronium group $(P<0.01)$

alcuronium $(P<0.05)$. The NMB and train-of-four ratio were comparable in both groups at extubation. The number of patients having a train-of-four ratio of $<70$ per cent ten minutes after the reversal was four in the atracurium and 13 in the alcuronium-group $(P<0.01)$.

The atracurium-patients had a greater train-of-four ratio in the recovery room than the alcuronium-patients although they arrived in the recovery room earlier (Table II). It took significantly longer for the alcuroniumpatients to express a train-of-four ratio of 70 or 90 per cent following neostigmine (6 vs $13 \mathrm{~min}$ and 10 vs $26 \mathrm{~min}$, respectively; $P<0.01$; Table II and Figure 1).

\section{Discussion}

This study was designed to evaluate, under clinical circumstances, the neuromuscular block and the train-offour ratio from the beginning of anaesthesia until full recovery in patients paralyzed with atracurium or alcuronium. Patients had an average NMB of 32 per cent and a train-of-four ratio of 50 per cent at the time when the anaesthetists regarded extubation to be safe. The NMB was $<10$ per cent in most patients when they arrived in the recovery room five minutes later, but the train-of-four ratio was still depressed especially among patients who had received a long-acting agent, alcuronium.

Studies in adults have shown that patients paralyzed with a long-acting muscle relaxant show a greater incidence of residual NMB in the recovery room than patients given an intermediate-acting muscle relaxant. ${ }^{3-6}$ Our results indicate that the same is true for paediatric patients. In the adult studies, pancuronium and gallamine was used as a long-acting muscle relaxant. We used alcuronium which has a clinical duration of effect comparable with pancuronium. ${ }^{7}$ The present study is the first where NMB was monitored and maintained at a preselected level throughout anaesthesia while the resi-



FIGURE 2 The relation between the time to reach a train-of-four (TOF) ratio of 90 per cent following neostigmine $50 \mu \mathrm{g} \cdot \mathrm{kg}^{-1}$ and the level of neuromuscular block (NMB) at the time of reversal. The more profound the NMB at the time of reversal the longer becomes the time to reach a train-of-four ratio of 90 per cent $(r=0.850, P<$ 0.001 ). If NMB is $>80$ per cent at the time of reversal then patients who have received atracurium express faster recovery than patients who have received alcuronium $(P<0.001)$.

dual effects of two muscle relaxants were compared. This made it possible to have comparable NMB at the end of surgery when neostigmine was given. Therefore, differences between residual NMB in the recovery room cannot be explained by unequal muscle paralysis at the time of reversal. The explanation for the difference probably depends upon the different recovery profiles of NMB following an intermediate-acting or a long-acting muscle relaxant.

Originally, Katz noticed that the more intense the neuromuscular block at the time of its reversal the longer it took to reach full recovery. ${ }^{8}$ Recently, Meistelman et $a l$. found a similar pattern of recovery times when they evaluated reversal of different levels of vecuroniuminduced NMB in children. ${ }^{9}$ Our data for both atracurium and alcuronium confirm these findings. It is noteworthy that our data for atracurium are comparable with those of vecuronium in the study of Meistelman et al. ${ }^{9}$ Furthermore, Figure 2 shows that patients given alcuronium recover significantly more slowly to a train-of-four ratio of 90 per cent than patients given atracurium when the NMB was $>80$ per cent at the time of reversal. The more profound the NMB, the greater the difference becomes. In clinical practice, an anaesthetist cannot always wait for spontaneous recovery from NMB before its reversal at the end of surgery. Therefore, the reversal may take place from deep levels of NMB which are not optimal for patient care. If an intermediate-acting muscle relaxant is used, the rate of recovery following neostigmine is fast. On the contrary, eight patients in the alcuronium group required longer than $30 \mathrm{~min}$ to achieve 90 per cent recovery of the train-of-four ratio.

A train-of-four ratio of $>70$ per cent has been regarded to indicate clinically satisfactory postoperative neuromus- 
cular recovery ${ }^{10,11}$ although even at that level airway protection may be inadequate. ${ }^{12}$ We did not ask our patients to perform tests of muscle power or airway protection but regarded a train-of-four ratio of 90 per cent as an indicator of complete recovery of the NMB. The major proportion of neuromuscular receptors is occupied by the muscle relaxant even at that recovery level. ${ }^{13}$ Based on our results, patients paralyzed with atracurium are free of residual effects of the muscle relaxant earlier than patients given alcuronium. This is not only related to a fast spontaneous recovery rate of NMB following an intermediate-acting muscle relaxant ${ }^{14}$ but also to a faster recovery rate of NMB following neostigmine in patients paralyzed with a shorter-acting agent (see Figure 2).

An interesting finding in our study was the level of NMB at the time the anaesthetist decided to remove the tracheal tube from the patient. The average train-of-four ratio at that time was only 50 per cent and was not related to the muscle relaxant used. It seemed that the timing of extubation was determined exclusively by the patient's ventilatory muscle activity. The patients given atracurium reached the required muscular activity faster and their tracheas were extubated earlier than those of patients given alcuronium. One reason for such early tracheal extubation may be greater recovery of diaphragmatic paralysis than hand muscle paralysis during the reversal of neuromuscular block. ${ }^{15}$ The clinical practice to extubate the trachea at the time of incomplete neuromuscular recovery probably puts the patient at risk of inadequate ventilation during transportation to the recovery room. Twenty-four of the atracurium-patients had a train-offour ratio of $>70$ per cent before they arrived in the recovery room compared with only half of the alcuronium patients.

Patients who had received atracurium arrived in the recovery room earlier and even then showed greater train-of-four ratios than patients paralyzed with alcuronium. All atracurium patients had a train-of-four ratio of 90 per cent within $23 \mathrm{~min}$ of the administration of neostigmine as compared with only 15 of the 30 alcuronium patients. Therefore, we consider that atracurium provides the patient with a safer recovery profile of neuromuscular block than alcuronium.

In conclusion, patients have significant neuromuscular block at the time of extubation following balanced anaesthesia. The recovery profile from the residual neuromuscular block is more predictable if an intermediate-acting muscle relaxant is used instead of a long-acting muscle relaxant. Children seem to have similar risks of residual curarization in the recovery room as adults.

\section{References}

1 Viby-Mogensen J, Jorgensen BC, Ordning $H$. Residual curarization in the recovery room. Anesthesiology 1979; 50: 539-41.

2 Beemer GH, Rozental P. Postoperative neuromuscular function. Anaesth Intensive Care 1986; 14: 41-5.

3 Bevan DR, Smith CE, Donati F. Postoperative neuromuscular blockade: a comparison between atracurium, vecuronium, and pancuronium. Anesthesiology 1988; 69: 272-6.

4 Andersen BN, Madsen JV, Schurizek BA, Juhl B. Residual curarization: comparative study of atracurium and pancuronium. Acta Anaesthesiol Scand 1988; 32: 79-81.

5 Brull SJ, Silverman DG, Ehrenwerth J. Problems of recovery and residual neuromuscular blockade: pancuronium vs. vecuronium. Anesthesiology 1988; 69: A473.

6 Howardy-Hansen P, Rasmussen JA, Jensen BN. Residual curarization in the recovery room: atracurium versus gallamine. Acta Anaesthesiol Scand 1989; 33: 167-9.

7 Shanks $C A$. Pharmacokinetics of the nondepolarizing neuromuscular relaxants applied to calculation of bolus and infusion dosage regimens. Ancsthesiology 1986; 64: 72-86.

8 Katz RL. Clinical neuromuscular pharmacology of pancuronium. Anesthesiology 1971; 34: 550-6.

9 Meistelman C, Debaene B, d'Hollander A, Donati $F$ Saint-Maurice $C$. Importance of the level of paralysis recovery for a rapid antagonism of vecuronium with neostigmine in children during halothane anesthesia. Anesthesiology 1988; 69: 97-9.

10 Ali HH, Wilson RS, Savarese JJ, Kitz RJ. The cffect of tubocurarine on indirectly clicited train of four muscle response and respiratory measurements in humans. $\mathrm{Br} \mathbf{J}$ Anaesth 1975; 47: 570-4.

11 Miller RD. How should residual neuromuscular blockade be detected? Anesthesiology 1989; 70: 379-80.

12 Pavlin EG, Holle RH, Schoene RB. Recovery of airway protection compared with ventilation in humans after paralysis with curare. Anesthesiology 1989; 70: 381-5.

13 Waud $B E$, Waud DR. The margin of safety of neuromuscular transmission in the muscle of the diaphragm. Anesthesiology 1972; 37: 417-22.

14 Meretoja OA, Kalli $I$. Spontancous recovery of neuromuscular function after atracurium in pediatric patients. Anesth Analg 1986; 65: 1042-6.

15 Lebrault C, Chauvin M, Guirimand F, Duvaldestin $P$. Antagonism of vecuronium-induced diaphragmatic neuromuscular blockade by neostigmine. Ancsthesiology 1988; 69: A513. 